\title{
Assessment of the Fertility Pattern of Women in North Western Nigeria
}

\author{
Gerald I. Onwuka*, Wasiu A. Babayemi, Yusuf Idris, Tolu O. James. \\ Department of Mathematics (Statistics Unit) Kebbi State University of Science and Technology, Aliero, Nigeria \\ Corresponding Author*
}

\begin{abstract}
Fertility behavior is conditioned by both biological and social factors. Knowledge of fertility pattern gives insight into drivers of human fertility. The paper investigated the birth pattern of women in Kebbi State, North Western Nigeria. A total of 2,256 questionnaires were distributed to the women of child bearing age using simple random sampling across five local government areas. The aim of the study was to analyze the pattern of fertility among age group of women of childbearing age and the effects of some exogenous variables on the fertility of women in the state. Poisson regression was applied for the positive count value recorded. The results from the analysis revealed that experience of birth or history of birth, financial reliant, obesity, individual age are highly significant to the study and have direct impact on fertility. Despite our ability to breed continuously, all human populations exhibit variation in reproduction.
\end{abstract}

Keywords: Birth pattern, Child-bearing age, Exogenous Variables, Poisson Regression.

\section{INTRODUCTION}

A reproductive life of a woman extends from about 15 to 49 years( i.e child bearing age), and few women reproduce below this age group, all women in this age group do not have uniform reproduction. There are some biological, economical and socio-cultural variables which mainly hinders reproduction of women. In some countries there have been efforts to establish registration of births in a simple list of village, local government or even state in an attempt to collect vital statistics (vital registration) by periodic measurement (Bell 1997). The knowledge of the age pattern of fertility of certain country or state has various uses in demography; it is not only improving the fertility but also helps in population projection, project fertility component implementation of policies as well as strengthening the family planning program. The paper shall provide a model on fertility pattern. The model will help in identifying the fertility pattern of the country as proclaimed in some previous literature in the eighteenth century that the size of a nation's population is always limited by economic resources and possibilities. If a country gets richer, women will get better income possibilities and the cost of raising children will increase. Fertility analysis is important in understanding current, past and future trends of the population size, composition and growth. Information on the fertility levels, pattern and trends experienced by a country is important for socio economic planning, monitoring and evaluation programs. According to Hinde and Mturi (2000), fertility rate is high in sub-Saharan Africa (SSA) than any part of the world, mainly due to high economic and social value attach to children. The low economic development is contributing to high infant and child mortality (Cutler et al, 2006)

High fertility rates could be one of the major deterrents to sustained economic growth in sub-Saharan Africa (SSA) countries and this effect can be examined at each level of population. In developing countries, study on the pattern of fertility is most important topic because of its direct relevance to the government for planning and making polices. The illeffects of population growth can be examined at macro and micro levels. Different fertility regulation mechanism such as modern contraceptives, termination of pregnancy, delayed marriages have contributed much towards fertility reduction in urban (Markos, 1997). Therefore the level of fertility in kebbi state, North Western, Nigeria will be examined in order to ascertain the influential factors on the fertility of women.

Fertility analysis is important in understanding current, past and future trends of the population size, composition and growth. Information on the fertility levels, pattern and trends experienced by a country is important for socio economic planning, monitoring and evaluation programs. In Europe, the declining population growth and the ageing population causes concern about the future of the welfare status, while the same trend in developing countries is regarded as good news because high population growth usually is seen as closely linked with low economic and human development (Gudbrandsen, 2010). Guilmoto and Rajan (2001) tried to understand the mechanism behind the regional variation in fertility. They took fertility as a regionalized variable, i.e. a variable which is assumed to be spatially continuous. The maps based on geospatial data revealed that spatial variation in fertility is far from random. Fertility decline began in periphery along the coast and in the extreme south and then spread progressively towards interior. Morgan (2002) made a comparative study of Muslim and non-Muslim fertility in Asian countries. The study revealed that Muslims have more children, and are more likely to want another child and are consistently less likely to use contraceptive. Tsegaye (2010) assessed the association between employment status and fertility of married people in the context of Ethiopia. The analysis was made based on the 2000 and 2005 Ethiopian Demographic and Health survey data. The findings showed 
that there was an insignificant relationship between women employment status and fertility behavior at a country level.

Al-Awad and Chartouni (2010) examined the factors that have contributed to the decline in fertility in Gulf Cooperation Council countries in recent years, employing data from the 2008 U.A.E Household Expenditure survey, however the research analyzed the determinants of fertility using a Poisson fertility model on the data collected through questionnaire and established that low-income has effect on fertility. In the view of Feyisetan and Bankole (2012), fertility behavior is conditioned by both biological and social factors. And as in other traditional African societies, several factors have contributed to sustain relatively high levels of fertility in Nigeria. These factors include high level of infant and child mortality, early and universal marriage, early child bearing as well as child bearing within much of the reproductive life span, low use of contraception and high social values placed on child bearing.

Angeles (2010) regression analysis of fertility decline in the period 1960-2000, established that GDP per capita has negative coefficient but its estimated effect is far weaker than mortality and education. One possible explanation for this relatively weak estimated effect is that the true effect of income growth on fertility is heterogeneous, raising the demand for children in some subgroups and lowering it in others (as economic theory would predict). Feyisetan and Bankole (2012), set out to ascertain declining fertility trend in Nigeria and identified the key determinants that facilitated such trend. They concluded that a sustained fertility transition had commenced in Nigeria. They found out that the trend was more emphatic in the South than in the Northern part of the country. The survey revealed that there was clamor to reduce the desired family size. Other important factors that determine the fertility transition included: use of contraception, changes in nuptiality patterns, particularly in the proportion marrying before age 20, and increased education of women. Further declines in desired family size were coupled with increased use of contraception for limiting, rather than as a substitute for traditional birth spacing methods, increases in age at marriage and education of women generated further declines in fertility.

Ushie (2009) in their study examined the socio-cultural and economic determinants of fertility differentials in rural and urban Cross River State, Nigeria with specific focus on Calabar and Bendi communities. Survey design utilized data from a sample of eight hundred and eighty respondents which was drawn using purposive, quota and systematic sampling techniques. The study elicited data via structured questionnaire and focused group discussions (FGD). Hypotheses of the study were tested using Bi-variate and Multi-variate techniques. Findings revealed that age at entry into marital union, contraceptive use and educational level significantly determined fertility differentials between rural and urban communities in Cross River State. The study recommended among others that public enlightenment campaigns on the use of contraceptives and proper family planning should be embarked upon by relevant agencies.

Onoja and Ikpotokin (2012) tested effects of some determinants of fertility on child bearing women to determine the level of fertility in Nigeria using data from the 2008 Nigerian Demographic Health Survey (NDHS). Data on 20,974 women were extracted from the 2008 NDHS data and analyzed using descriptive statistics and Poisson regression. Women with no education and those with secondary school education had 1.36 times risk and $17 \%$ increases in fertility (respectively) over those with higher education. Rural women were 1.02 times more likely to be at risk of high fertility compared to women in urban areas. Fertility level in Nigeria is higher in the rural areas than in the urban areas while level of education of women negatively impacted on their risk of having high fertility.

According to Olokor (2012) Nigeria have a total fertility rate (5.7) that is high and higher than many other countries of about similar level of development. (see the National Population Commission (NPC)): North-West and North-East having high total fertility rates." Adolescent childbearing has many negative health, social, and demographic consequences. Women who start having children at a young age often do not complete secondary school, limiting their future employment possibilities and other life choices. Additionally, early childbearing often results in larger families and reduced economic circumstances. Nationwide, $23 \%$ of girls age 15-19 have either already had a live birth or are pregnant with their first child.

Bratti (2002) used data from the 1993 Survey of Household Income and Wealth conducted by the Bank of Italy in order to estimate a reduced form purist model of female marital fertility and labor force participation. It focused in particular on the effect of formal education on both fertility and labor force participation, and accounted for the potential endogeneity of education. After estimating an education regression and testing for weak exogeneity of education and controlling for a wide range of characteristics of a woman's family and marital background, the research did not find any residual evidence of endogeneity of education with labor force participation and fertility. Estimates showed that increasing education up to the upper secondary level exerted a positive effect on marital fertility at ages 21-39 and that highly educated women postponed fertility and had a higher labor market attachment.

In the Middle East, Khraif (2002) assessed determinants of fertility in Saudi Arabia, using a regression analysis. He found that age at marriage and woman's education are apparently the most important determinants of fertility behavior. Ayebale (2005) examined the determinants of cohort fertility in Uganda. The study utilized three datasets from the Uganda Demographic and Health Surveys (UDHS) carried out in 1988/89, 1995 and 2001. These datasets were combined to from four cohorts. To establish the determinants of cohort 
fertility preference, a Poisson regression model was used. The study found that women in the rural areas had higher fertility preferences than their counter parts in urban areas. Women who had attained secondary level of education and above had lower fertility preference than those with no education at all. In the study, increasing age of mother was associated with increasing fertility preference. Increasing age at first birth was associated with decreasing fertility preference.

EI Lahga and Olfa (2008) assessed the main socioeconomic determinants of the household fertility decision in Tunisia, referring to Becker and Lewis hypothesis (1973). A count data model, which reasonably describes observed completed fertility patterns, was used. A Poisson regression model of household fertility decision was applied. To accommodate the under-dispersion exhibited in the sample a model based on squared polynomial expansion of Poisson density was also used. They found that husband characteristics were almost as important as those of wives in determining fertility decision.

\subsection{Need For The Study}

North Western Nigeria has high rate of fertility and there are numerous consequences on the household level. For instance, women may not have enough time to give proper care to their young children. High fertility rates could be one of the major deterrents to sustained economic growth. This study will tend to contribute to the literature using recent cross sectional data. In addition, factors that determine fertility are measured as count data (i.e. children ever born to a woman by the time of the research) and are assessed using the recently developed count data modeling; namely, the Poisson regression model. Our result could be used in policy formulation towards strengthening the family planning programs. Summarily, the paper examined the relationship between fertility of women and exogenous variables; It also assessed the impact of those variables on the fertility of women and determined the pattern of fertility of women with Kebbi State as a case study.

\section{MATERIALS AND METHODOLOGY}

\subsection{Data Collection and Exploration}

The study covered five Local Government Areas (LGA)., namely: Argungu, Aleiro, Yauri, Bagudo and Bunza of which 2286 questionnaires were distributed and Poisson regression was used to determine the relationship between fertility and some selected exogenous variables. However the study is limited to the women in child bearing age in the study area. This study estimated a reduced form equation for the number of children ever born.

\subsection{The Poisson Model}

Factors determining fertility measured as count data (i.e children ever born to a woman by the time of the survey) are assessed using the recently developed count data modeling; namely, the poison regression model, it is a recently adopted model used to investigate the relation between the number of children ever born and the socioeconomic and demographic variables of women obtained from a given survey (Winkelmannand Zimmermann, 1995). Poison regression is one of the robust models for the analysis of discrete data that are based on the assumption that the dependent variable is Poissonly distributed and its logarithm is a linear function of the independent variables. An important feature of this model is that the heterogeneity of $y$ is modeled as a deterministic function of the explanatory variables, therefore the randomness is intrinsic and not due to other factors as in the classical regression model. Given the discrete and nonnegative nature of our dependent variable, the OLS model is clearly inappropriate as it specifies a conditional mean function $x^{\prime} \beta$ that may take negative values and a variance function that is homoscedastic. If the conditional mean function is an fact $\exp \left(x^{\prime} \beta\right)$, the OLS estimator is inconsistent for $\beta$ and the computed OLS output gives the wrong asymptotic variance matrix (El Lahga and Olfa, 2008). The dependent variable is a count variable denoting the number of children ever born to a spouse which takes on non-negative integer values. The expected value of the count variable $(y)$ conditional on a set explanatory variables $\mathrm{x}$ is modeled.

$$
\mathrm{E}(y / x)=e^{\left(x^{\prime} \beta\right)}
$$

The specification above ensures that $\mathrm{E}(y / x)>0$ thus, the number of children ever born to a spouse conditional on $\mathrm{x}$ is the Poisson distribution with probability density of

$P(Y=y / x)=\frac{e^{-e\left(x^{\prime} \beta\right)} e^{\left(x^{\prime} \beta\right)}}{y !} \quad$ Where $\mathrm{y}=0,1,2, \ldots \mathrm{N}$

The maximum likelihood Poisson fertility equation is the specified as

$L(\beta)=\sum_{i=1}\left\{y_{i} x_{i} \beta-e^{x_{i} \beta}\right\}$

The explanatory variables $x_{i}{ }^{\prime} S$ in the fertility equation refer to socio economic variables describing household and women's characteristics.

The full model is therefore given as:

$$
\mu_{i}=e^{\beta_{o}+\sum_{j=1}^{k} \beta_{j} x_{j}}
$$

Where:

$\mu=$ the expected number of children per woman $\mathrm{I}$; e $=$ the base of natural logarithms;

$\beta_{0}=$ the intercept; $\beta_{j}{ }^{\prime} S=$ regression coefficients; $X_{j}{ }^{\prime} S$ $=$ Explanatory variables.

\subsection{Method and Area of Data Collection}

Primary information is required for estimating fertility, like number of live births by mothers in particular age group during the specific time interval, the educational attainment of mothers, access to media (like computer and Hand set), age of mothers, class status. Therefore, the method used for data collection is questionnaire and Kebbi State is the area of study. 


\subsection{Sample Selection}

In order to avoid bias during the study Local Government areas in the state were arranged in alphabetical order and numbers were allotted to each Local Government, then table of random numbers was used to select five Local Governments out of twenty one (21) Local Governments in the state, having done this the following Local Government (Argungu, Aleiro, Badugo, Bunza and Yauri) were sampled and used in the study.

\subsection{Variables Definition}

Total number of children ever born is modeled as a function of socio economic and demographic variables which include the following independent exogenous variables: Age (min: 15years and a maximum of 49years.) Access to media: (Handset, Computers, Newspaper). Class Status (This is a wealth indicator and it is measured as poor, poorer, middle, richer, richest; these variables are expected to have impact on the fertility of women). Work Status ( labour-work of the interviewed females) Education Status(The educational attainment is directly related to her opportunity cost of time and inversely related to the fertility decision)/ This inverse relationship is expected to be stronger and the number of years of schooling by female are important variables to consider in the analysis of fertility.

\section{RESULTS ANALYSIS AND DISCUSSION}

\subsection{Transformation of Variables}

The Descriptive Statistics such as the Mean, Median, Skeweness, Kurtosis and Standard Deviation were examined. Tables and Figures were plotted and discussed.

\subsubsection{Count Number of Birth (Nbirth=Y)}

It represents the number of count of fertility in Kebbi State.

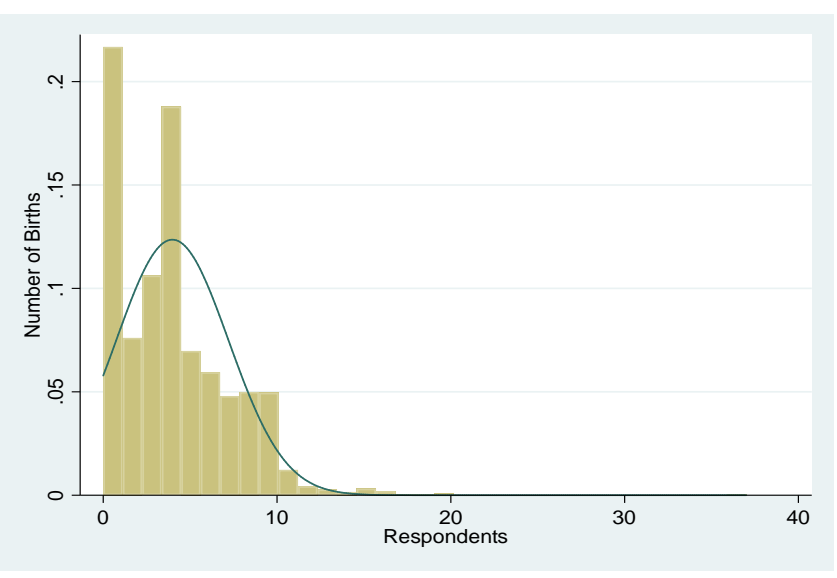

Figure 3.01 Distribution of Number Birth

The result in 3.01 above revealed the distribution of number of births which clearly showed that the variable in question is skewed to the right, meaning that the variable needs transformation to be normalized, However the transformation showed that natural logarithm of number of births will be a better for the analysis.

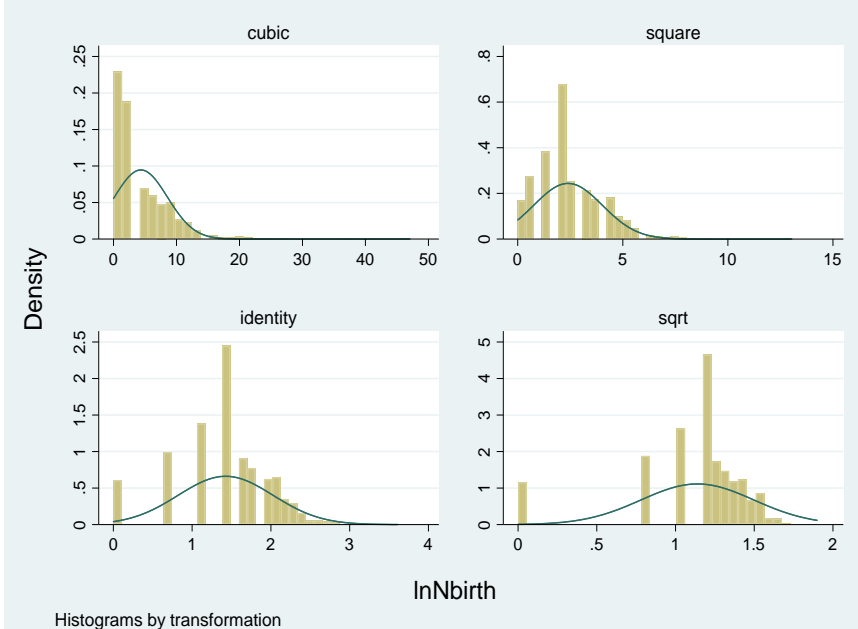

Figure 3.02 Set of Transformations Considered

The results in Figure 3.02 showed the set of transformations considered in the study of which natural logarithm of the variable taken.

\subsubsection{Age of Women}

This is the recorded age of women within the fertility age (child bearing age 15 - 49) that were considered in the survey

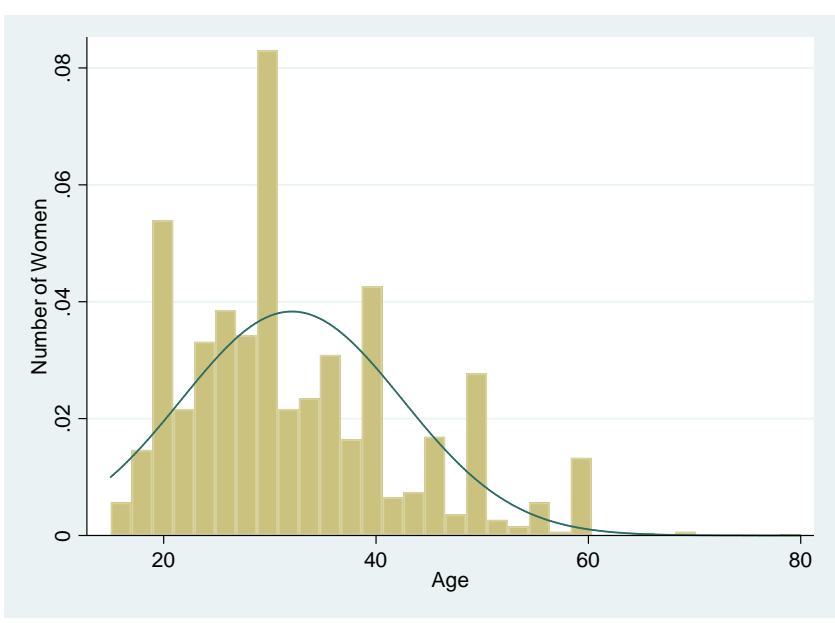

Figure 3.03 Distribution of Age of Women.

The Figure showed the transformation of age of women within the fertility period and it clearly revealed it is evenly distributed along the curve.

\subsubsection{Age group of women}

The result in figure 3.04 below revealed the distribution of age groups of women which are divided in to eight group with equal class interval and equal sizes. 


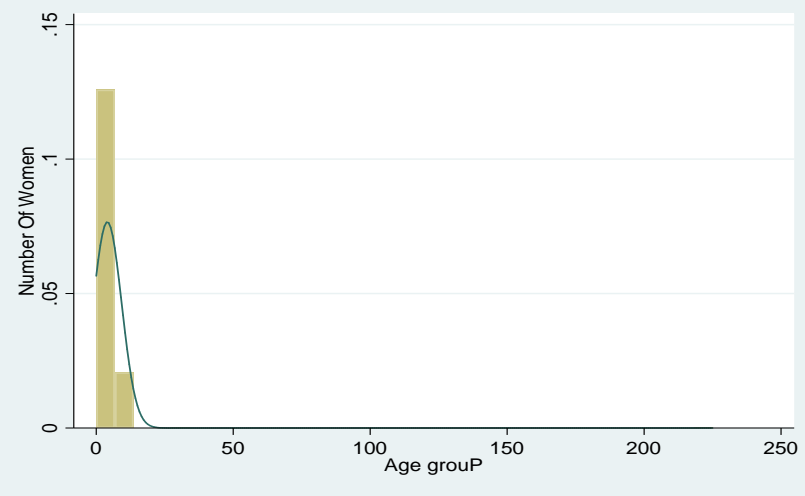

Figure 3.04 Distribution of Age Group of Women

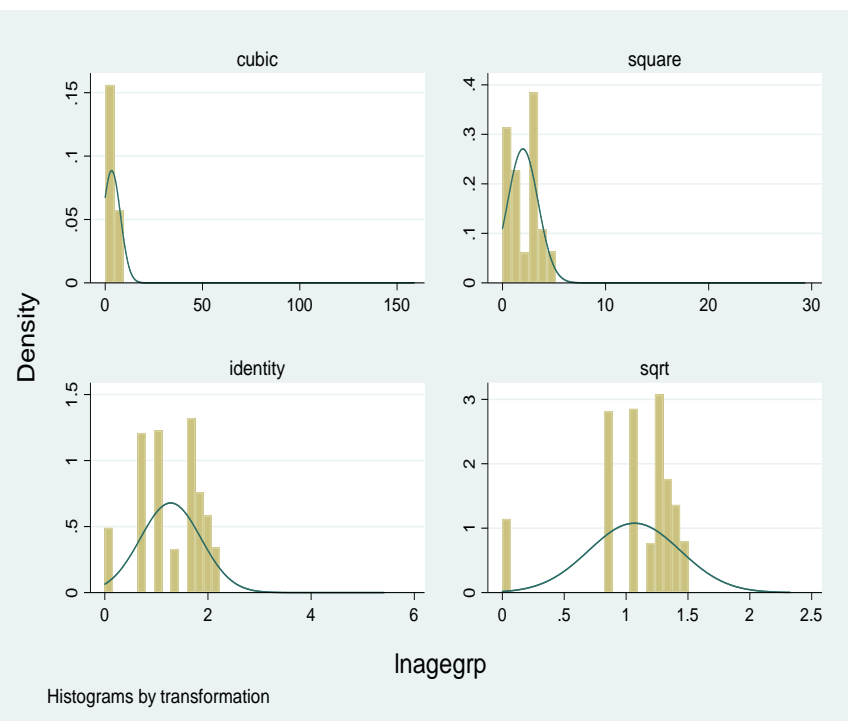

Figure 3.05 Set of transformation of Age Group of women that were considered.

This showed other transformations that were considered of which natural logarithm is used.

\subsubsection{School Attainment of Women}

Presentation of recorded school attainment of women within the fertility period in kebbi state

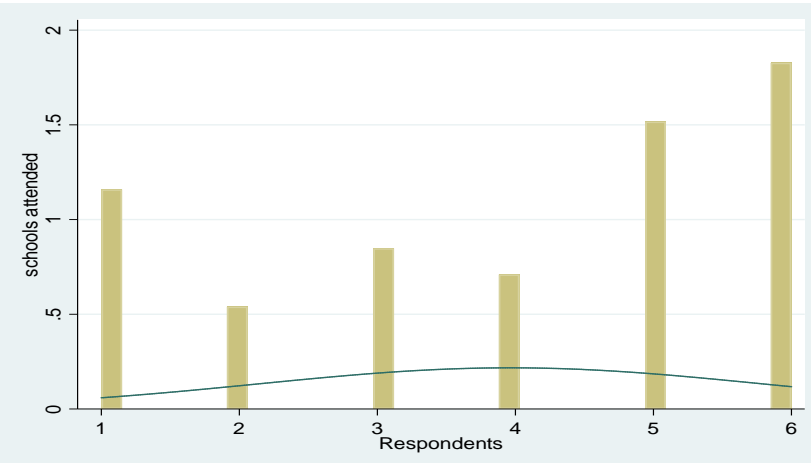

Figure 3.06 Distribution of School Attainment of Women

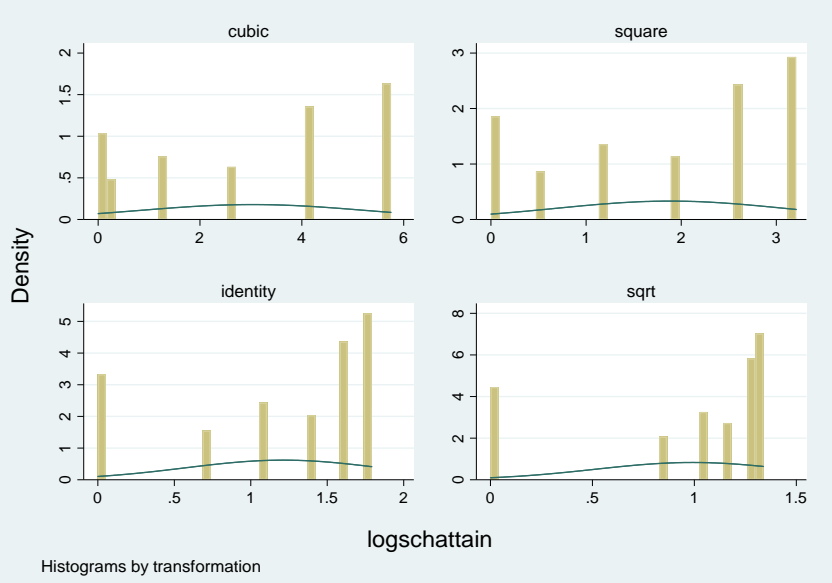

Figure 3.07 Distribution of general logarithm of School Attainment

Results in Figure 3.07, revealed more spread points in logtransformation of school attainment which was used in the analysis.

\subsubsection{Class Status of Women}

Recorded class status of women of reproductive age represented in figures below

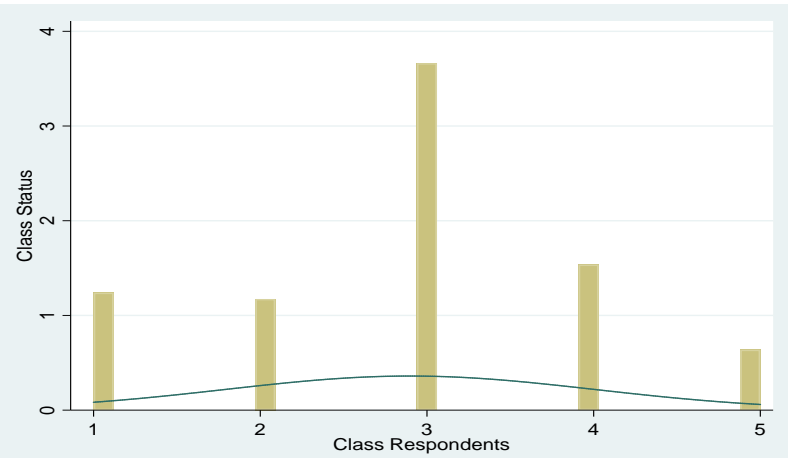

Figure 3.08 Distribution of Class Status of Women

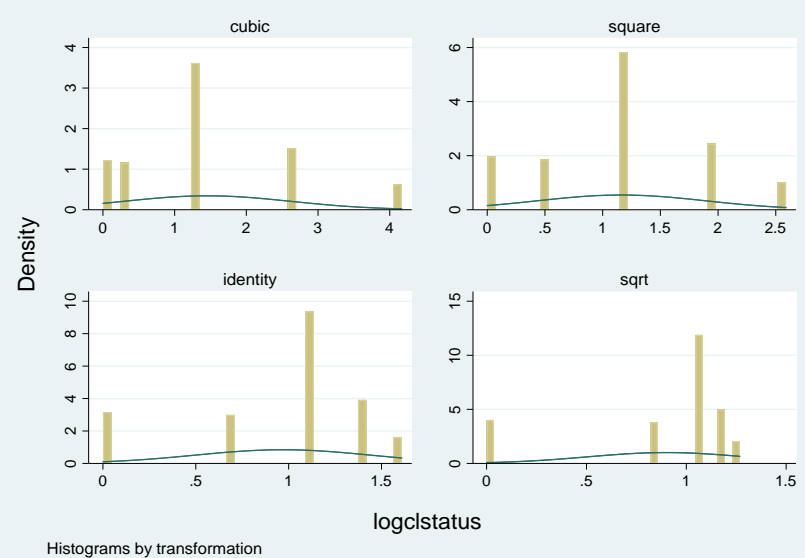

Figure 3.09 Showing The Transformation That were Considered in The Class Status 
Results in Figure 3.09 revealed more spread points in logtransformation of class status of women which was used in the analysis.

\subsection{Descriptive Statistics of the Variables Used in the Study}

Table 3.01 Distribution of School Attainment

\begin{tabular}{|c|c|c|c|}
\hline $\begin{array}{c}\text { School } \\
\text { Attainment }\end{array}$ & Frequency & Percentage & $\begin{array}{c}\text { Cumulative } \\
\text { Frequency }\end{array}$ \\
\hline No Education & 395 & 17.56 & 17.56 \\
\hline $\begin{array}{c}\text { Incomplete } \\
\text { Prim }\end{array}$ & 184 & 8.18 & 25.73 \\
\hline $\begin{array}{c}\text { Complete } \\
\text { Primary }\end{array}$ & 289 & 12.84 & 38.58 \\
\hline Incomplete Sec & 242 & 10.76 & 49.33 \\
\hline Complete Sec & 517 & 22.98 & 72.31 \\
\hline Tertiary & 523 & 27.69 & 100 \\
\hline Total & 2250 & & \\
\hline
\end{tabular}

Kelly and Allen (1996) suggested that school attainment should be considered as variable in the regression fertility study, the distribution of the school attainment in Table 3.01 above indicated that $17.56 \%$ of the women of reproductive age have no education and $8.18 \%$ have not completed their primary school education though $12.84 \%$ have completed primary education as revealed from the table. Similarly, $10.76 \%$ of women have incomplete secondary school education while $22.98 \%$ among women of reproductive age have complete secondary education, and $27.69 \%$ of women have tertiary education. Based on the preliminary analysis made on the responses from the questionnaires distributed, the following results were obtained:

Distribution of Financial Status of women: it was revealed that $47.20 \%$ of women are not financially reliant and $52.80 \%$ of women in reproduction age are financially reliant.

Distribution of Class Status of women: it was revealed that $15.02 \%$ of women are poor and $14.22 \%$ of them are poorer. Similarly, $44.40 \%$ of women are middle class and $18.62 \%$ of women are richer with $7.73 \%$ in the richest class.

Distribution of women working: The distribution of working status of women in childbearing age revealed that $60.53 \%$ of women are unemployed with only $39.47 \%$ of women were employed.

Distribution of Women Reading Newspapers: The distribution of women reading newspapers. $64.31 \%$ of the women are not reading newspapers and $35.69 \%$ of women are newspaper readers.

Distribution of Women Accessible to handset or computer: The result showed that $30.93 \%$ of the women have no access to handset or computer.

Distribution of Women Smoking habit: Smoking is one of the variables considered to have vital role in the research because of some beliefs in the existing literature that smoking habit may tend to hinder the reproductive system of child-bearing mothers (Gudbrandsen, 2010). Our findings revealed that $19.29 \%$ of the women are smoking.

Distribution of Drugs Addiction of Women: This showed that $74.62 \%$ of women are not drugs addicted with only $25.38 \%$ addicted to drugs.

Distribution of Women Taken Orthodox Medicine: This revealed that $32.13 \%$ of the women are not using orthodox medicine while $67.87 \%$ of the women have been using orthodox medicine for fertility treatment.

Distribution of women with Diabetes: It revealed that $80 \%$ of women have no diabetes and only $20 \%$ are diabetes positive.

Distribution of women with obesity: it revealed that only $35.24 \%$ are obsessed.

Distribution of women living with HIV: This indicated that $64.76 \%$ of women are HIV negative and $35.24 \%$ of women are HIV positive.

Distribution of Age group of women: Reproduction of women is always determined by age of women and it reflects the characteristic of life cycle therefore it can condition some of the explanatory variable used in the research though age is a continuous variables with minimum of 15 years and the maximum of 49years (Childbearing Age 15 -49).

Table 3.02 Distribution of number of children ever born by mothers

\begin{tabular}{|c|c|c|c|}
\hline $\begin{array}{c}\text { Number of } \\
\text { children ever } \\
\text { born }\end{array}$ & Frequency & Percentage & $\begin{array}{l}\text { Cumulative } \\
\text { Frequency }\end{array}$ \\
\hline 0 & 429 & 19.07 & 19.07 \\
\hline 1 & 118 & 5.24 & 24.31 \\
\hline 2 & 192 & 8.53 & 32.84 \\
\hline 3 & 268 & 11.91 & 44.76 \\
\hline 4 & 474 & 21.07 & 65.82 \\
\hline 5 & 176 & 7.82 & 73.64 \\
\hline 6 & 150 & 6.67 & 80.31 \\
\hline 7 & 121 & 5.38 & 85.69 \\
\hline 8 & 126 & 5.60 & 91.29 \\
\hline 9 & 68 & 3.02 & 94.31 \\
\hline 10 & 57 & 2.53 & 96.84 \\
\hline 11 & 31 & 1.38 & 98.22 \\
\hline 12 & 11 & 0.49 & 98.71 \\
\hline 13 & 7 & 0.31 & 99.02 \\
\hline 14 & 4 & 0.18 & 99.20 \\
\hline 15 & 8 & 0.36 & 99.56 \\
\hline 16 & 5 & 0.22 & 99.78 \\
\hline 17 & 1 & 0.04 & 99.82 \\
\hline 18 & 1 & 0.04 & 99.87 \\
\hline 20 & 2 & 0.09 & 99.96 \\
\hline 37 & 1 & 0.04 & 100.00 \\
\hline
\end{tabular}


History of fertility of set of women investigated is paramount in this type of study as suggested by (Girosi and King, 2008). The results in Table 3.02 revealed distribution of number of children ever born by mothers that were investigated. $19.07 \%$ of them were reported not to have given birth before. Remaining percentages were distributed among child bearing ones.

Table 3.03 Result of the Poisson Regression Estimates

\begin{tabular}{|lccccccc|}
\hline \multicolumn{1}{|c}{ InN birth Coef.S td. Err. } & $\mathrm{Z}$ & \multicolumn{4}{c|}{$\mathrm{P}>\mid \mathrm{z}[[95 \%$ Conf.Interval] } \\
\hline \multicolumn{1}{|c|}{ Ebirth-.1966182 } & .0567618 & -3.46 & 0.001 & -.3078693 & -.0853671 \\
\hline agegrp1 & -.117349 & .2639302 & -0.44 & 0.657 & -.6346286 & .3999587 \\
\hline agegrp2 & -.1174112 & .2102217 & -0.56 & 0.576 & -.5294382 & .2946158 \\
\hline agegrp3 & -.0596062 & .1598257 & -0.37 & 0.709 & -.3728589 & .2536466 \\
\hline agegrp4 & -.0744319 & .0943988 & -0.79 & $0.430-.2594501$ & .1105864 \\
\hline agegrp5 & -.0031927 & .1285559 & -0.02 & $0.980-.2551576$ & .2487723 \\
\hline agegrp6 & .0412773 & .1018298 & 0.41 & $0.685-.1583054$ & .2408599 \\
\hline agegrp7 & .0575816 & .0882091 & 0.65 & $0.514-.1153051$ & .2304682 \\
\hline lnage. & .6882043 & .2424771 & 2.84 & 0.005 .212958 & .1163451 \\
\hline schattain1 & .1610895 & .0680591 & 2.37 & 0.018 .0276961 & .2944828 \\
\hline schattain2 & .1863022 & .0893061 & 2.09 & 0.037 & .0112656 & .3613389 \\
\hline schattain3 & .1851364 & .0736653 & 1.85 & 0.064 & -.0079813 & 2807813 \\
\hline schattain4 & .1149535 & .0777737 & 1.48 & $0.139-.0374801$ & .2673872 \\
\hline schattain5 & .0443349 & .0586192 & 0.76 & $0.449-.0705566$ & .1592264 \\
\hline finrlnt & -.0907982 & .0431724 & -2.10 & $0.035-.1754147$ & -.0061818 \\
\hline clstatus1 & -.0124321 & .091156 & -0.14 & 0.892 & -.1910946 & .1662304 \\
\hline clstatus2 & .0021899 & .0903978 & 0.02 & $0.981-.1749866$ & .1793664 \\
\hline clstatus3 & -.0340998 & .0766104 & -0.45 & $0.656-.1842534$ & .1160537 \\
\hline clstatus4 & -.1134345 & .0814085 & -1.39 & 0.163 & -.2729921 & .0461232 \\
\hline rdnews & .0599195 & .0503835 & 1.19 & 0.234 & -.0388304 & 1586695 \\
\hline Acsshndset & -.0121483 & .0474316 & -0.26 & 0.798 & -.1051125 & 0808159 \\
\hline smoke & .018631 & .0638876 & 0.29 & 0.771 & -.1065863 & .1438484 \\
\hline drgadct & -.0237902 & .0603404 & -0.39 & 0.693 & -.1420552 & .0944747 \\
\hline othodox & .0036299 & .0456742 & 0.08 & 0.937 & -.0858898 & .0931496 \\
\hline diabetic & .0611463 & .0610503 & 1.00 & 0.317 & -.0585102 & .1808027 \\
\hline obessed & .0324255 & .04779810 & .68 & 0.004 & -3636101 & .1261081 \\
\hline Hiv & -.1016362 & .0710134 & -1.43 & 0.152 & -.2408199 & .0375474 \\
\hline _cons & -1.874967 & .9497257 & -1.97 & 0.048 & -3.736395 & .0135383 \\
\hline
\end{tabular}

Result in Table 3.03 Revealed the number of observations = $1,821, \operatorname{chi}^{2}(27)=170.40$, Prob $>\operatorname{chi}^{2}=0.0000$ and Pseudo $R^{2}$ $=0.0372$. It's also 1 indicate that experience of birth or history of birth (Ebirth), individual age (lnage), school attainment 1 and school attainment 2, financial reliant and obesity are highly significant to the study of fertility regression. The result obtained may not be necessarily surprising as from the literature review history of fertility of women counts. Age group tends to be insignificant but individual age (lnage) tends to be highly significant but not age group. Women without any formal education (School attainment 1) and women who have no complete primary school education (school attainment 2) were highly significance at 5\% level of significance. However, women with complete primary education (school attainment 3), was significant at $10 \%$ level of significance. Possibly school attainment 1 and 2 are mostly housewives without any formal education.

In addition with the inclusion of handset, obesity financial reliant, smoking only, financial reliant and obesity tend to be significant at 5\% level. However, class status, reading of newspaper, intake of orthodox medicine was statistically insignificant to the fertility study.

The overall model specification is highly significant in that prob $>\mathrm{chi}^{2}=0.000$ and the $\log$ likelihood is -2203.618 , which specified that the model is adequately fitted.

The history of fertility or experience of birth on both women sides and their respective parents tend to show a negative impact on fertility of these women. The indication of this is that if their respective parents have low fertility there is tendency for decrease in the fertility life of these women. The results revealed $19.66 \%$ chance of reduction in fertility of such women.

Individual age tend to show a positive impact on fertility. The indication of this result is that between 15 to 49 years of individual ages of women studied, the fertility tends to be at its peak at 23 to 35 years. The result revealed $68.8 \%$ chance of increase on fertility level.

Financial reliant tend to show negative impact on the fertility. This implies the fact that women in the studied area might be fertility deficient as a result of lack of money or wealth to handle their daily needs. This might also possibly increase maternal and neonatal mortality rates in the area as discussed (Booth and Tickle, 2008). There is 9\% chance of the effect of this variable on the fertility of women.

School attainment tends to exert positive impact on fertility, education they say, is power. The literacy of mother may likely increase fertility. Literacy goes with awareness about 8$7 \%$ chance of this effect on the fertility.

Obesity tends to show negative impact and this implies about $3 \%$ chance effect on fertility.

Thus, the fertility of women in the studied area tend to follow a pattern that is most from the results obtained) likely to be affected by these significance determinants. 
Table 3.04: Incidence Rate Ratio

\begin{tabular}{|c|c|c|c|c|c|c|}
\hline InNbirth & IRR & Std. Err & $\mathrm{Z}$ & $\mathrm{P}>|z|$ & {$[95 \%$ Conf. } & Interval] \\
\hline Ebirth & .7387503 & .0561446 & -3.98 & 0.000 & .6365124 & .8574099 \\
\hline Agegrp1 & .7585812 & .2755924 & -0.76 & 0.447 & .3721866 & 1.546121 \\
\hline Agegrp2 & .8075731 & .2391274 & -0.72 & 0.470 & .4519973 & 1.442872 \\
\hline Agegrp3 & .9362677 & .2134466 & -0.29 & 0.773 & .5988892 & 1.463705 \\
\hline Agegrp4 & .8231167 & .1384869 & -1.16 & 0.247 & .5919013 & 1.144652 \\
\hline Agegrp5 & 1.003054 & .182454 & 0.02 & 0.98 & .7022509 & 1.432705 \\
\hline Agegrp6 & 1.083804 & .1572926 & 0.55 & 0.579 & .8154851 & 1.440409 \\
\hline Agegrp7 & 1.09583 & .142788 & 0.70 & 0.482 & .4848495 & 1.414672 \\
\hline Lnage & 1.839657 & .632511 & 1.77 & 0.076 & .9377274 & 3.609084 \\
\hline Schattain1 & 1.208504 & .1300233 & 1.76 & 0.078 & .9787394 & 1.492207 \\
\hline Schattain2 & 1.22357 & .1571939 & 1.57 & 0.116 & .9512036 & 1.573924 \\
\hline Schattain3 & 1.181774 & 0.1331467 & 1.48 & 0.138 & .9476153 & 1.473793 \\
\hline Schattain4 & 1.13086 & 0.1291323 & 1.08 & 0.281 & .9049013 & 1.414517 \\
\hline Schattain5 & 1.055248 & .1107013 & 0.51 & 0.608 & .8591310 & 1.296135 \\
\hline Finrlnt & .9050788 & .0525414 & -1.72 & 0.086 & .8077508 & 1.014154 \\
\hline Clstatus1 & 1.114684 & .2090136 & 0.58 & 0.563 & .7718689 & 1.609756 \\
\hline Clstatus2 & 1.115117 & .2070947 & 0.59 & 0.557 & .7748885 & 1.604731 \\
\hline Clstatus3 & 1.103312 & .1983712 & 0.55 & 0.585 & .7756314 & 1.569426 \\
\hline Clstatus4 & .9835152 & .192948 & -0.08 & 0.932 & .6695617 & 1.444680 \\
\hline Rdnews & 1.016417 & .0865624 & 0.19 & 0.848 & .8601610 & 1.201057 \\
\hline Acsshndset & .9669276 & .0590859 & -0.55 & 0.582 & .8577875 & 1.089940 \\
\hline Smoke & .9656738 & 0.103197 & -0.33 & 0.744 & .7831890 & 1.190678 \\
\hline Drgadct & .9244577 & 0.837006 & -0.87 & 0.386 & .7741393 & 1.103964 \\
\hline Orthodox & .9891355 & .0612275 & -0.18 & 0.860 & .8761257 & 1.116722 \\
\hline Diabetic & 1.073537 & 0.933152 & 0.82 & 0.414 & .9053743 & 1.272935 \\
\hline Obese & 1.065969 & .0666661 & 1.02 & 0.307 & .9429967 & 1.204978 \\
\hline Hiv & .8289795 & .0867641 & -1.79 & 0.073 & .6752333 & 1.017733 \\
\hline cons & .2027318 & .2732767 & -1.18 & 0.236 & .0144386 & 2.846542 \\
\hline
\end{tabular}

Note:_cons estimate baseline incidence rate.

Table 3.04 Indicates that number of observations is $1,806, \mathrm{chi}^{2}$ $=1.2393$, Prob $>\mathrm{Chi}^{2}=0.0000$ and Pseudo $\mathrm{R}^{2}=0.0468$. Furthermore due to history of fertility from the parent, the result showed that there is tendency of decrease of about $27 \%$ in every unit of fertility. The indication is that if their respective parents have low fertility there is tendency for decrease in fertility life of these women.

Incidence rate ratio revealed that there is likelihood of $84 \%$ increase in fertility of women due to individual age in the studied area. This implies the fact that women in the study area might be fertility deficient as a result of lack of money or wealth to handle their daily need.

Incidence rate ratio also clearly indicate a possibility of positive impact on the fertility due to school attainment/educational level of women in the area with about $21 \%, 22 \%, 18 \%, 13 \%$ and $5 \%$ respectively. Financial reliant of women also indicate to be negatively important from the incidence rate ratio. Furthermore due to incidence rate ratio there is indication that smoking habit has negative impact on the fertility of women of about $4 \%$ decrease.

\section{DISCUSION OF THE RESULTS}

The study investigated the relationship between fertility and some exogenous variables such as Experience of birth or history of fertility (Ebirth), age-group, individual age, work status, educational status of women, class status of women, intake of orthodox medicine and HIV. Aside from some of the variables in the existing literature, this study included use of handset, obesity, smoking, financial reliant, HIV and diabetes. The initial inspection of these variables showed that the variables must be transformed as suggested by (Tsegaye, 2010; Girosi and King, 2008; Booth and Tickle, 2008; Khraif, 2002; El Lahga and Olfa, 2008; Bratti 2002; Aldeiri and Vinci, 2007). Furthermore, the results obtained in Table 3.04 showed similar assertions with (Cameron, 1996) where Ebirth, age and school attainment are also significant. However work status, age group, reading of newspaper were insignificant in this study which contradicted (Cochrane, 1980; Ayebale, 
2005; Guzman, 1994; Becker and Lewis, 1973), where these variables were highly significant which indicate that the pattern to which women of child bearing age in Kebbi State must consider include the fertility history or experience of birth, individual age (linage) financial reliant, obesity, School attainment 1 and school attainment 2 . The discrepancies in the two results might likely due to the different study area.

Financial reliant, obesity, factors included in the regression showed highly significance in the study area. Nevertheless the inclusion of the use of handset, diabetes, HIV, Smoking, do not affect the regression.

The history of fertility or experience of birth on both women sides and their respective parents tend to show a negative impact on fertility of these women. The indication of this is that if their respective parents have low fertility there is tendency for decrease in the fertility life of these women. The results revealed $19.66 \%$ chance of reduction in fertility of such women as discussed by (Aldeieri and Vinci, 2007).

Individual age tend to show a positive impact on fertility. The indication of this result is that between 15 to 49 years of individual ages of women studied, the fertility tends to be at its peak at 23 to 35 years. The result revealed $68.8 \%$ chance of increase on fertility level.

Financial reliant tend to show negative impact on the fertility. This implies the fact that women in the studied area might be possible fertility deficient as a result of lack of money or wealth to handle their daily needs. This might also possibly increase maternal and neonatal mortality rates in the area which is in line with (Booth and Tickle, 2008; Bratti, 2002; El Lahga and Olfa 2008). There is $9 \%$ chance of the effect of this variable on the fertility of women.

School attainment tend to exert positive impact on fertility education they say power. The literacy of mother may likely increase fertility. Literacy goes with awareness about 8-7\% chance of this effect on the fertility.

Obesity tends to show negative impact and this implies about $3 \%$ chance effect on fertility.

Thus, the fertility of women in the studied area tends to follow a pattern that is most likely to be affected by these significant determinants.

\section{CONCLUSION}

Having studied the relationship between fertility and some exogenous variables that determine the fertility behavior of women in Kebbi State, the results revealed that experience of birth or history of fertility, financial reliant, obesity, individual age, zero education level and women with incomplete primary school education were significant at 5\% level. The history of fertility or experience of birth on women and their respective parents tend to show a negative impact on fertility of these women. The indication of this is that if their respective parents have low fertility there is tendency for decrease in the fertility life of these women. The results revealed $19.66 \%$ chance of reduction in fertility of such women. Individual age tend to show a positive impact on fertility. The indication of this result is that between $15-49$ years of individual ages of women studied, the fertility tends to be at its peak at $23-35$ years. The result revealed $68.8 \%$ chance of increase on fertility level. Financial reliant tend to show negative impact on the fertility. This implies the fact that women in the studied area might be possible fertility deficient as a result of lack of money or wealth to handle their daily needs. This might also possibly increase maternal and neonatal mortality rates in the area. There is $9 \%$ chance of the effect of this variable on the fertility of women. School attainment tends to exert positive impact on fertility, education they say power. The literacy of mother may likely increase fertility. Literacy goes with awareness about $8-7 \%$ chance of this effect on the fertility. Obesity tends to show negative impact and this implies about $3 \%$ chance effect on fertility. Thus, the fertility of women in the studied area tends to follow a pattern that is most likely to be affected by these significant determinants. The indication of this result is that the birth pattern of the women of child bearing age in Kebbi State is most likely to be affected by these determinants. Thus, it was recommended from this study that the Government should sensitize the women in this area on the need to educate them on these crucial determinants.

\section{REFERENCES}

[1] Al-Awad, M and Chartouni, C. (2010). Explaining the declaiming in fertility among citizen of the G.C.C countries: the case of the U.A.E institute for Social and Economics Research. Working paper

[2] Aldeiri, L. and Vinci, C. P. (2007). "An Investigation of the Relationship between the number of children and education in Italy" Brussels Economic Review, 2007, 49(4);

[3] Angeles, L. (2010). Demographic Transition: Analysing the effect of mortality on fertility" Journal of Population Economics 23: 99120

[4] Ayebale L. (2005). "Determinants of cohort fertility preference in Uganda," capacity building programme, Uganda.

[5] Bratti, M. (2002). "Labour Force Participation and Marital Fertility of Italian Women: the Role of Education" Department of Economics, University of Warwick (UK).

[6] Bell, W. (1997),"Comparison and assessing time series methods for forecasting age-specific Fertility and mortality rates", Journal of Official Statistics vol. 13.

[7] Becker, G. S. and Lewis, H. G. (1973). "On the Interaction between the quantity and Quality of Children" Journal of Political Economy 8, 279-288

[8] Booth, H., and Tickle, L. (2008) mortality modeling and forecasting: A review of methods", The Australian Demographic and social Research Institute.

[9] Cameron, A. and Trivedi, P. (1996). "Economic Models based on count data: Comparison and Application of some Estimators and Test" Journal of Applied Econometrics.

[10] Culter, D., Deaton, A. and Muney, A. (2006),"The Determinants of mortality", The journal economic perspectives, Vol. 20.

[11] Cochrane, S. H. (1980) "The effect of education on health" world bank staff working paper.

[12] EI Lahga and Olfa, (2008).“ A Socioeconomic Analysis of Fertility Determinants with Count Data Models: The case of Tunisia" Tunisia Institute for Social and Economic Rsearch, Working paper No. 1

[13] Feyisatan, Bamikale J. and A. Bankole (2012). Fertility Transition in Nigeria: Trends and prospects Revised Bankole Paper. 
[14] Girosi, F. and King, G. (2008), Demographic forecasting, Princeton: Princeton university press.

[15] Gudbrandsen, N.H., (2010). "The impact of wealth and Female autonomy on Fertility Decision in Nepal: An Econometric Analysis" Working papers No.1. Chr. Michelsen Institute (CMI)

[16] Guilmoto, C. Z. and Rajan, S. I. (2001).Spatial pattern of fertility transition in Indian districts.Population and Development Review, 27(4), 713-738

[17] Guzman, J. M., (1994). The onset of Fertility Decline in Latin America.In The Onset of Fertility Transition in sub-Saharan Africa.Locoh T. and V Hertrich (Ed).IUSSP.

[18] Hinde, A. and Mturi, A. J. (2000). "Recent Trends in Tanzania Fertility" population Studies, 54 (2): 177-191.

[19] Khraif, R., (2002). "Fertility in Saudi Arabia: its Levels and Demographic, Social, Economic and Geographic Determinants" Al Darah Journal 28 (2): 9-84

[20] Kelly, V. and Allen, C. (1996) "The consequences of Rapid Population Growth on Human Resource Development: The Case of Education." In the Impact of Population Growth on Well-Being in Developing Countries.
[21] Markos, E., (1997). Demographic Response to Ecological degradation and Food Insecurity. Amsterdam: Thesis Publishers.

[22] Morgan, S. P. (2002). Muslim and non-Muslim difference in female autonomy and fertility: Evidence from four Asian countries. Population and Development Review, 28(3), 515-537.

[23] Olokor, F. (2012), Federal Government of Nigeria Worries Over Higher Fertility Rate, Seeks Review of Population Policy.

[24] Onoja, M.A and Ikpotokin, O. (2012). Modeling the Determinant Fertility among Women of Childbearing Age in Nigeria: Analysis Using Generalized Linear Model Approach, International Journals of Humanities and Social Science.

[25] Tsegaye T. (2010). Cross Sectional Study of Women Employment and Fertility in Ethiopia. Master's Thesis, Department of Economic History, Lund University.

[26] Ushie, M. A (2009). Fertility Differentially in Urban and Rural Nigeria: A Comparative Study of Calabar and Bendi Communities in Cross River State, Nigeria. Unpublished Doctoral Thesis, University of Calabar-Nigeria.

[27] Winkelmann R., and F. Zimmermann, (1995). "Recent Developments in Count Data Modeling: Theory and Application" Journal of Economic Surveys. 9(1): 1-24. 